\title{
Pecan Cultivar Conversion by Grafting onto Roots of 70-Year-old Trees
}

\author{
I.E. Yates \\ Russell Research Center, Agricultural Research Service, U.S. \\ Department of Agriculture, Athens, GA 30613 \\ Darrell Sparks \\ Department of Horticulture, University of Georgia, Athens, GA 30602 \\ Additional index words. Carya illinoinensis, propagation, lateral roots, IBA
}

\begin{abstract}
Scion wood of 'Desirable' pecan [Carya illinoinensis (Wangenh.) K. Koch] was grafted onto the lateral roots of 70-year-old 'Van Deman' seedling rootstocks for evaluation as an alternative to planting nursery-grown trees for orchard cultivar conversion. Grafting treatments included application of IBA, method of grafting, position of graft, and grafting time. Survival was higher for grafts treated with IBA than those without IBA, for modified bark grafts positioned beneath the soil line than for either modified hark grafts positioned above the soil line or inlay grafts, and for grafts made 6 to 8 weeks after budbreak than later in the season. Techniques developed in this study demonstrate that cultivar conversion of $>75 \%$ is possible. Chemical name used: lH -indole-3-butyric acid (IBA).
\end{abstract}

Orchards within a $200-\mathrm{km}$ radius of Albany, Ga., account for $\approx 46 \%$ of the total U.S. production of pecans (Wood et al., 1990). Many pecan orchards in this area were planted from 1910 to 1920 . Most of the orchards were planted to 'Alley', 'Pabst', 'Schley', and/or 'Stuart' propagated on seedling rootstocks (Ken Knight, 1970). All of these cultivars are successful as mature trees. However, some orchards were planted, either intentionally or inadvertently, with cultivars (e.g., 'Frotscher' and 'Teche') that have become commercially unacceptable mainly due to poor kernel quality (Sparks, 1990). Old orchards with cultivars that produce poor-quality nuts need to be replaced because production costs often exceed profits (Westberry et al., 1989). Likewise, undesirable cultivars intermixed in orchards with

Received for publication 28 Aug. 1991. Accepted for publication 4 Feb. 1992. We gratefully acknowledge the technical assistance of Lamar Jenkins, Donnie Maxey, and Joyce Lambert and the cooperation of Frank P. Wetherbee and use of his pecan trees at Flint River Pecan Co., Albany, Ga. Trade names are used in this publication to provide specific information. Mention of a trade name does not constitute a guarantee or warranty of the product or an endorsement by the U.S. Dept. of Agriculture over other products not mentioned. The cost of publishing this paper was defrayed in part by the payment of page charges. Under postal regulations, this paper therefore must be hereby marked advertisement solely to indicate this fact. predominantly good cultivars reduce the overall market value of the good nuts because of mixing with poor-quality nuts at harvest. Thus, growers suffer financial losses regardless of whether these poor-quality cultivars are in a solid stand or mixed in the orchard with good cultivars.

Altering the cultivar composition in orchards is an expensive, long-term investment. The classic replacement methods are either to top-work or remove trees of nonprofitable cultivars and replant with nurserygrown trees of a more profitable cultivar, such as 'Desirable'. Top-working mature trees is labor-intensive both in requiring up to 30 or more grafts per tree and long-term aftercare. Top-working usually is considered to be cost-prohibitive. Replanting costs include

Table 1. IBA effect on survival and vigor of 'Desirable' shoots propagated by a modified bark graft onto lateral roots of mature pecan trees.

\begin{tabular}{lccc}
\hline \hline $\begin{array}{l}\text { Criteria } \\
\text { analyzed }\end{array}$ & $\begin{array}{c}\text { Year } \\
\text { grafted }\end{array}$ & $+\mathrm{IBA}^{\mathrm{z}}$ & -IBA \\
\hline Survival (\%) & 1989 & $60^{*}$ & 39 \\
& 1990 & $60^{* * *}$ & 37 \\
Vigor index $^{\mathrm{y}}$ & 1989 & $14.1^{\mathrm{Ns}}$ & 12.5 \\
& 1990 & $8.6^{\mathrm{NS}}$ & 9.7 \\
\hline
\end{tabular}

${ }^{2}$ One percent and $2 \%$ (by weight) in talc applied in 1989 and 1990 , respectively.

yVigor index $=$ length/diameter of the shoot. Ns,*,***Nonsignificant or significant at $P \leq 0.01$ and 0.0001 , respectively, within years. 
Table 2. Tree conversion and graft survival based on grafting method on mature lateral roots of pecan.

\begin{tabular}{lcccc}
\hline \hline $\begin{array}{l}\text { Grafting } \\
\text { method }^{\mathbf{z}}\end{array}$ & $\begin{array}{c}\text { Trees } \\
\text { grafted } \\
\text { (no.) }\end{array}$ & $\begin{array}{c}\text { Grafts } \\
\text { inserted } \\
\text { (no.) }\end{array}$ & $\begin{array}{c}\text { Trees } \\
\text { convertedy,x } \\
(\%)\end{array}$ & $\begin{array}{c}\text { Grafts } \\
\text { surviving } \\
(\%)\end{array}$ \\
\hline Bark (above) & 14 & 28 & 14 & 11 \\
Bark (below) & 17 & 34 & 59 & 32 \\
Inlay (below) & 5 & 10 & 0 & 0 \\
\hline
\end{tabular}

2Position of graft relative to soil line (indicated within parentheses).

Tree conversion based on at least one of two grafts surviving.

xMeans within column differ significantly at $P \leq 0.05$.
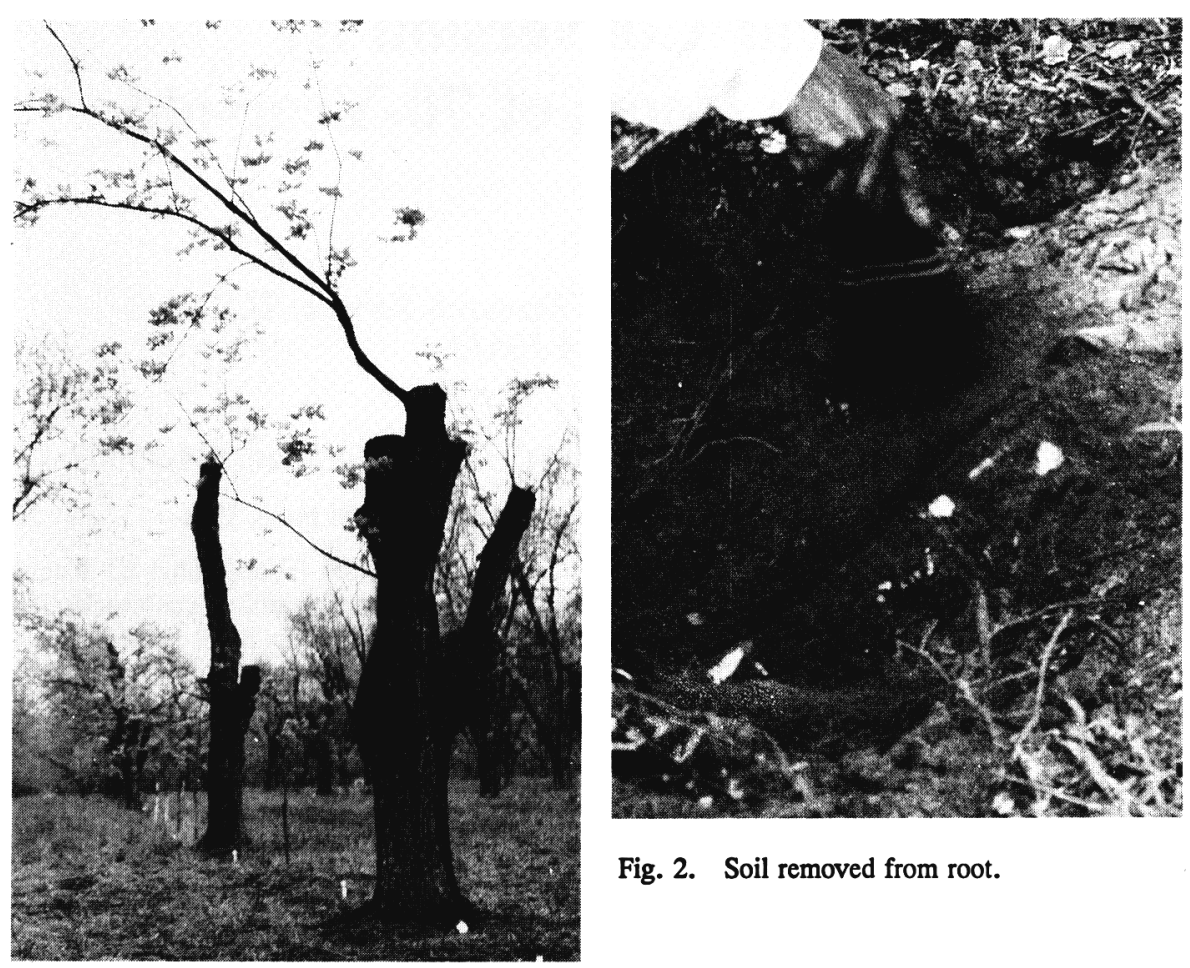

Fig. 2. Soil removed from root.

Fig. 1. Pollarded tree on which lateral root grafts were inserted in 1990.

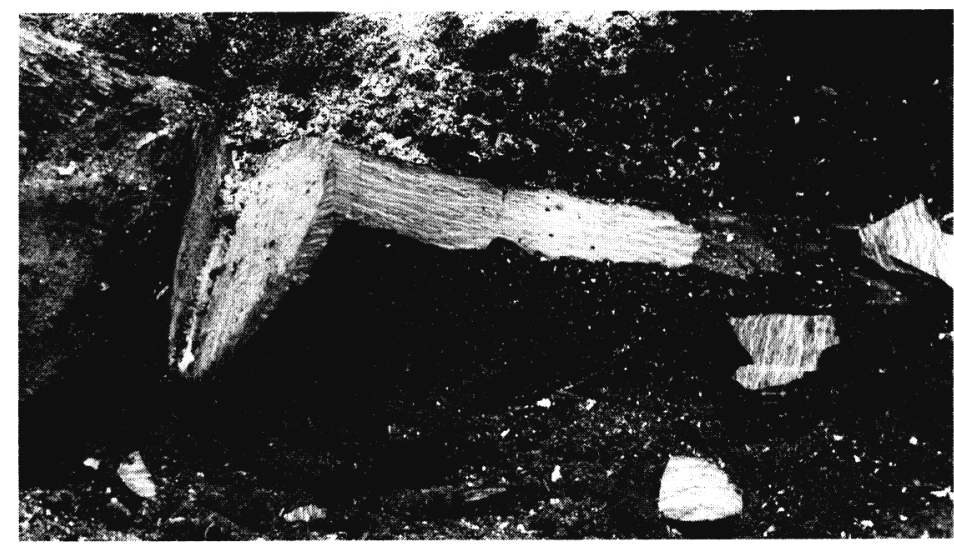

Fig. 3. Wedge and $\approx 1 \mathrm{~mm}$ surface of the lateral root bark removed.

tree and stump removal, purchasing and planting a new tree, plus the production costs between replanting and cropping.

Using the root system of the existing undesirable cultivar may be a method for getting an acceptable cultivar into production faster than replanting with a nursery-grown tree. One possibility would be to graft or bud onto sprouts growing from the stump of a felled tree. However, our observations show eral roots of existing mature trees.

Plant material. 'Desirable' scion wood was grafted onto lateral roots of 70-year-old seedling rootstock of 'Van Deman' trees growing in a commercial orchard in Baconton, Ga. Scion wood was collected in February of each year, wrapped in moist paper, and stored at 10C until used for grafting. Grafts were made in 1989 on intact trees and in 1990 on pollarded trees with the basal two or three branches remaining as life limbs (Fig. 1). Pollarding was done in February before the grafts were inserted. The time of graft insertion is expressed by both calendar date and weeks after budbreak (WAB). Budbreak occurred on 28 Mar. 1989 and 16 Mar. 1990.

Grafting procedures. Methods of grafting were a bark graft positioned on the root either above or below the soil line and an inlay graft positioned below the soil line. The rationale for positioning the graft below the soil line was based on observations of stump sprouts. Sprouts forming on lateral roots near or below the soil line were less likely to be broken by the wind than those arising from roots elevated above the soil line.

The procedure for inserting inlay grafts was as described by Soule (1985), in which the scion wood is trimmed to align with the cambial layers of a rectangular slot cut into the root. Because scion wood is inserted on stumps of felled trees in a typical bark graft (Soule, 1985), modifications were made for scion insertion into roots. The soil was removed from the root for grafts made below the soil line (Fig. 2). A wedge was cut from the lateral root with a chain saw to provide space for the graft (Fig. 3). The wedge was sloped to one side so that excessive sap would drain away from the grafting site. The top 1 $\mathrm{mm}$ surface of the lateral root bark was shaved (Fig. 3). The pith was exposed on the scion wood ( $\approx 15 \mathrm{~cm}$ long) by a cut beginning 3 $\mathrm{cm}$ from the top and continuing to the base so as to form a wedge. The scion wood was laid on the shaved bark to position cuts through the root bark along either side of the scion wood. The bark was peeled back to form a flap and the scion wood was dusted with IBA, if used, before insertion under the bark flap (Fig. 4). The scion was secured to the root with a nail through the bark flap. The graft site, with the exception of the uppermost bud on the scion wood, was covered with Trowbridge Grafting Wax (Walter E. Clark \& Son, Orange, Corm.) (Fig. 5). A double layer of aluminum foil was placed over the graft site and secured to the root with staples (Fig. 6).

IBA treatments, grafting methods, scion insertion time, and root bark thickness. Grafts, evaluated for effect of IBA, were made 24 May 1989 (8 WAB) on 13 trees divided into four replications of three or four trees each and 24 Apr. 1990 (6 WAB) on 35 trees divided into five replications with seven trees each. Each tree had two grafts inserted, one with and one without IBA (1\% IBA in 1989 and $2 \%$ IBA in 1990). IBA was mixed in talc (by weight) and applied to surfaces of the scion wood to be in contact with the root. Graft success was evaluated as percent shoot 


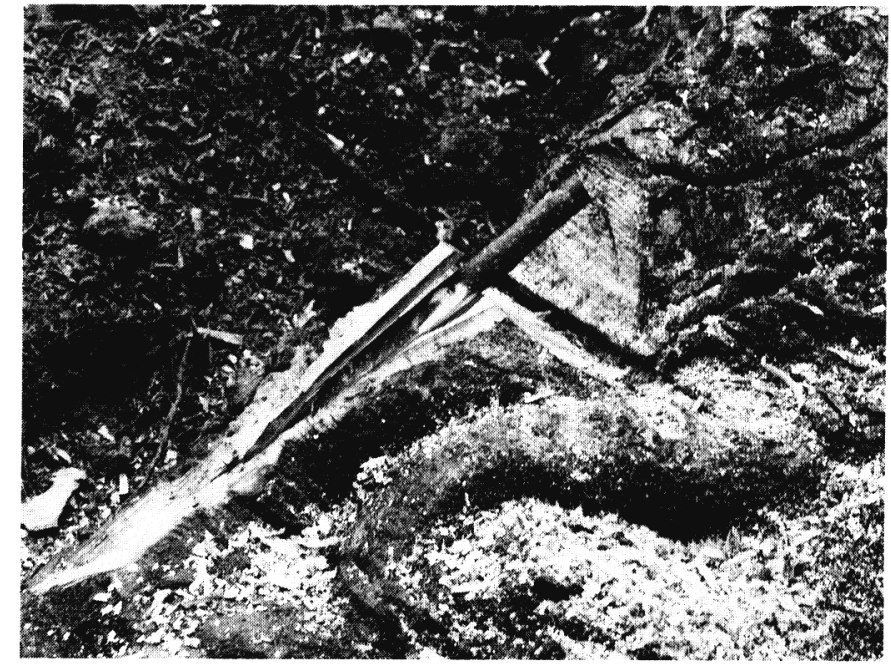

Fig. 4. Scion wood inserted beneath bark flap.

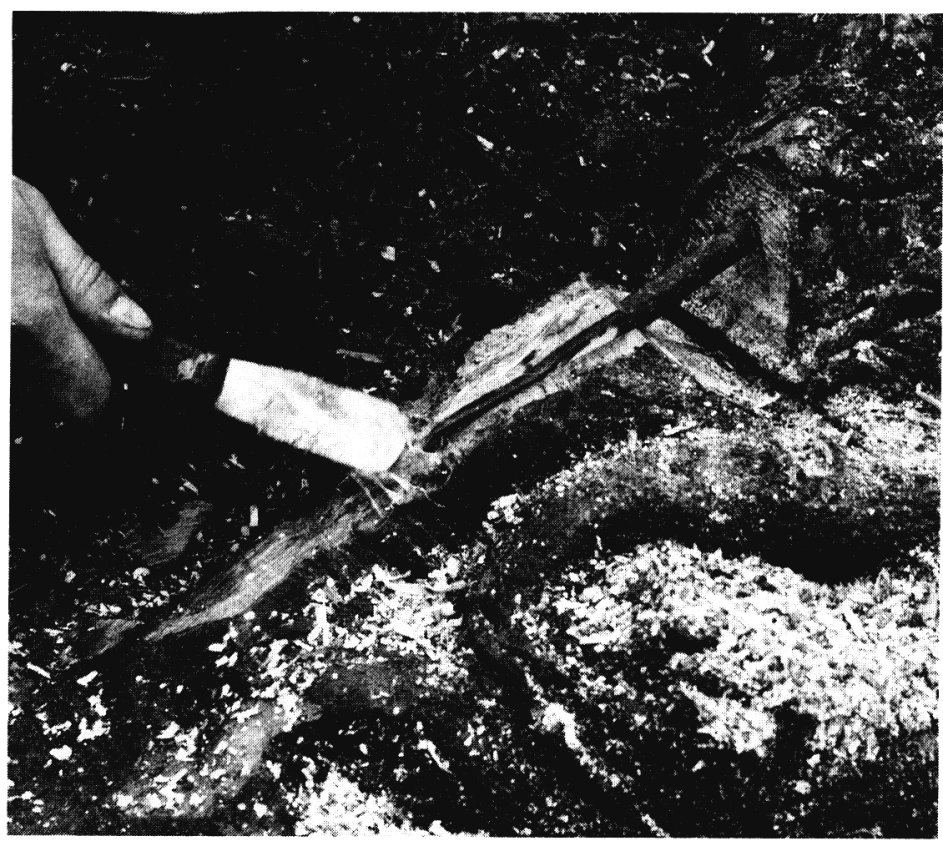

Fig. 5. Graft site covered with grafting wax.

survival and analyzed by the paired $t$ test with a random assortment of trees into replications. The IBA influence on vigor was expressed as shoot length/shoot diameter and was analyzed by the unpaired $t$ test. Comparisons were based on five shoots with IBA and eight shoots without IBA in 1989 and on 21 shoots with IBA and 13 shoots without IBA in 1990.

Grafting methods were evaluated on scions inserted on $10 \mathrm{Apr}$. (4 WAB) as modified bark grafts above and below the soil line and by inlaying. Scion wood was inserted in 14 trees as bark grafts above the soil line, 17 trees as bark grafts below the soil line, and five trees as inlay grafts. Each tree had two grafts. Data were analyzed by chi square.

The influence of scion insertion time on graft success was determined by comparing survival of scions inserted without IBA on 24 May (13 trees at $8 \mathrm{WAB})$ vs. 7 June (120 trees at $10 \mathrm{WAB}$ ) 1989 and $10 \mathrm{Apr}$. (36 trees at $4 \mathrm{WAB}$ ) vs. $24 \mathrm{Apr}$. (35 trees at $6 \mathrm{WAB}$ )
Table 3. Effect of time of grafting on survival of 'Desirable' shoots propagated by a modified bark graft on mature lateral roots of pecan. ${ }^{z}$

\begin{tabular}{lcc}
\hline \hline $\begin{array}{l}\text { Year } \\
\text { grafted }\end{array}$ & \multicolumn{2}{c}{$\begin{array}{c}\text { Date scion inserted: } \\
\text { Weeks after budbreak } \\
\text { (\% survival) }\end{array}$} \\
\hline 1989 & 24 May: 8 & 7 June: 10 \\
& $(39)$ & $(11)^{* *}$ \\
1990 & 10 Apr.: 4 & 24 Apr.: 6 \\
& $(22)$ & $(37)^{\text {NS }}$ \\
\hline
\end{tabular}

${ }^{\text {z }}$ Survival based on scions inserted without IBA treatment.

Ns,**Nonsignificant or significant at $P \leq 0.001$ within years.

other shoots were $<50 \mathrm{~cm}$ tall and $<10 \mathrm{~mm}$ in diameter. The variability in shoot vigor was not affected by IBA application (Table 1) and appeared to be primarily related to the exposure of the developing shoot to sunlight.

Cultivar conversion, based on the survival of at least one of the two grafts on a tree, was calculated for scion wood inserted on 24 May 1989 (8 WAB) and 24 Apr. 1990 (6 WAB). The percentage of trees converted from 'Van Deman' to 'Desirable' was $>75 \%$ for both years. These conversion calculations were based on experiments in which only one of the grafts was treated with IBA. A conversion of close to $90 \%$ might be possible if both grafts were treated with IBA because IBA increased graft survival by nearly $20 \%$ in 2 years of experimentation (Table 1).

The method of grafting and the position of the scion on the lateral root affected the success of cultivar conversion and graft survival (Table 2). The most successful method for both cultivar conversion and graft survival was the modified bark graft positioned beneath the soil line. No inlay grafts survived and few of the modified bark grafts made above the soil line were successful.

Graft survival depended on the time of scion insertion. The most suitable time for making grafts was apparently in late spring, $\approx 6$ to 8 weeks after budbreak (Table 3 ). Abrupt changes in graft survival may be confounded by factors, such as prevailing temperatures, other than time.

Root bark thickness has a dramatic effect on graft survival. Survival of grafts was highest $(74 \%)$ on roots with a bark thickness of 8.1 to $10.0 \mathrm{~mm}$ (Fig. 8). Survival decreased abruptly with either thinner or thicker bark.

Estimation of establishment costs on a pertree basis indicates that cultivar conversion by lateral root grafts is less expensive than replanting with a nursery tree. The cost of cutting down and removing the tree is common to both methods. Expenses specific to replanting are about $\$ 50.00$ for removing the stump, $\$ 8.00$ for buying a nursery tree, and $\$ 0.50$ planting costs. The expense specific to lateral root grafts is the grafting. The cost of grafting is $\$ 2.00$ per graft or $\$ 4.00$ for two grafts per tree. Minimum labor cost would be $\$ 1.00$ for soil removal from around the roots and cutting the wedge in preparation for the graft. However, assuming at least $10 \%$ 


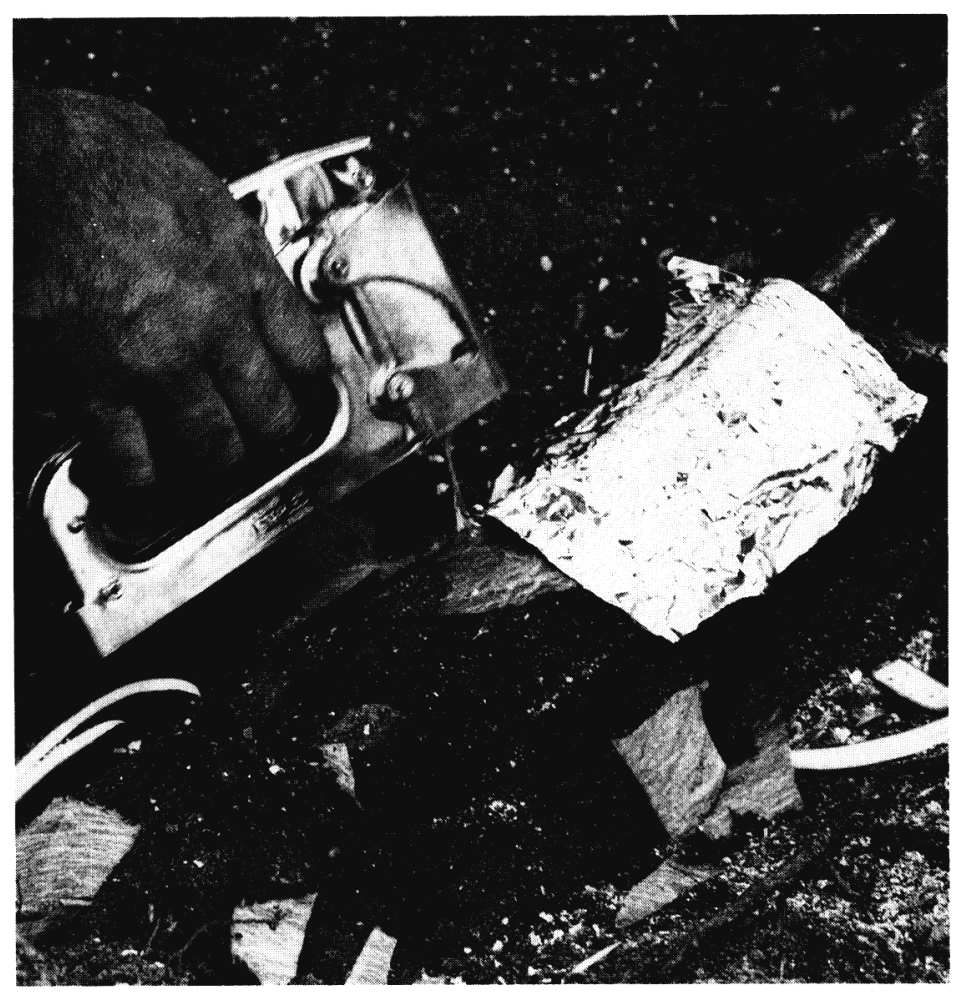

Fig. 6. Completed graft covered with aluminum foil.

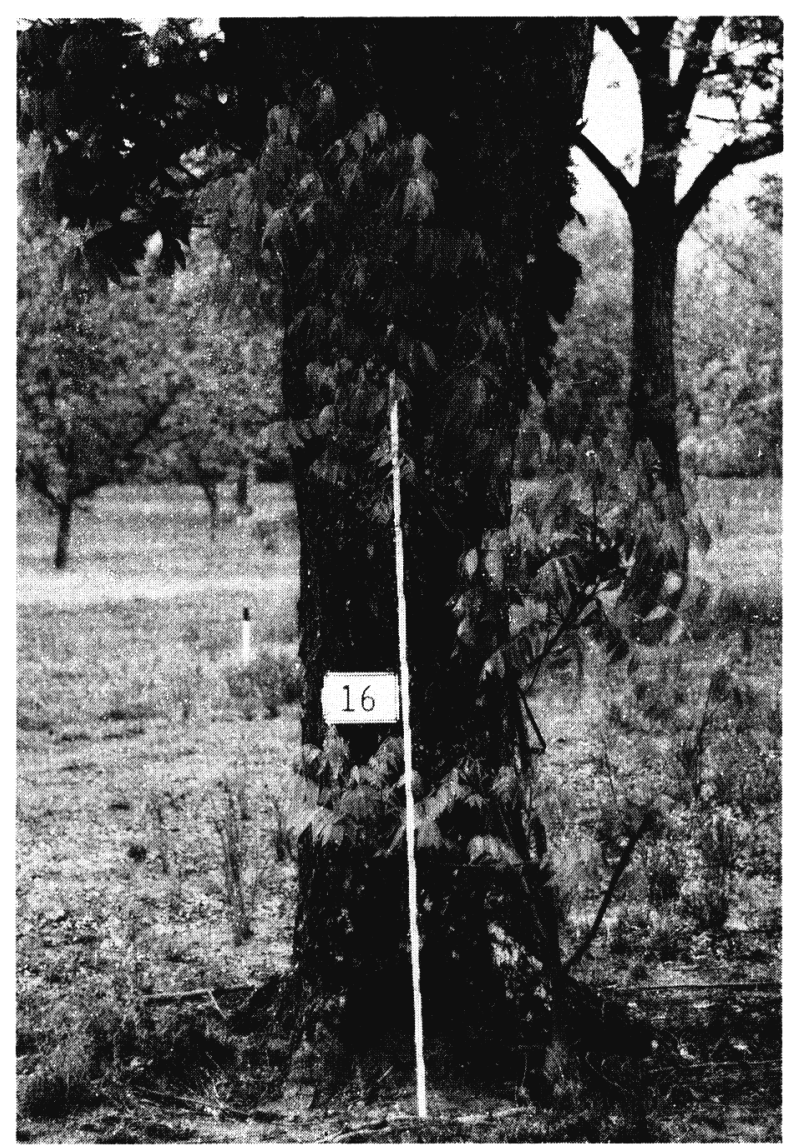

Fig. 7. Shoot growth at the beginning of the second growing season from a lateral root graft. White marker $=1.8 \mathrm{~m}$.

of the trees require grafting the second year, another $\$ 0.50$ would be invested, bringing the total cost per tree to about $\$ 5.50$ for latera1 root grafting in comparison to $\$ 58.50$ for replanting with a nursery tree. If the stump is not removed, as is sometimes the practice, replanting with a nursery tree would be only slightly higher, costing $\$ 8.50$.

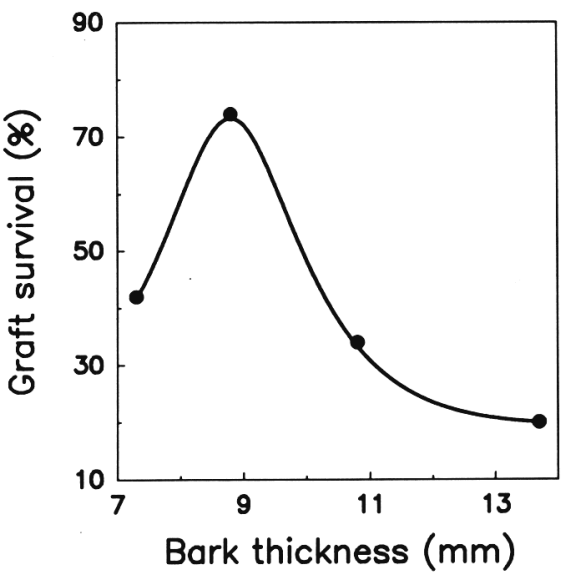

Fig. 8. Effect of bark thickness on graft survival. The relationship of graft survival to bark thickness is described by the equation $Y=1 /$ $[\mathrm{a}+\mathrm{bF} 1(\mathrm{x})]$, where $\mathrm{a}=0.0514, \mathrm{~b}=$ -0.0378 , and $F 1=$ Gaussian normal distribution equation. $P \leq 0.01$.

Disadvantages of grafting to lateral roots of mature trees include the apparent short time interval for grafting, the crucial dependence of success on bark thickness, and shading of grafts by the original tree, unless the graft was positioned for maximum sunlight exposure. The variability of shoot growth may be related to the exposure of the developing shoot to sunlight. Furthermore, the new tree often had to be tied to the trunk of the original tree. A potential problem is that shoots may not be regenerated from scion wood inserted on precut trees, because the lateral root grafts we analyzed were placed on intact or pollarded trees. Another possible disadvantage is damage to the young cultivar shoot by cold injury. Sparks and Payne (1977) demonstrated that cultivar trunks grafted at ground level were much more likely to suffer cold injury than seedling trunks. Injury of the new tree may occur also when the original tree is removed. In addition, as old trees are widely spaced (up to $37 \mathrm{~m}$ ), tree replacement by root grafts will require interplanting. If trees from root grafts grow faster than interplants, differential tree size will result. Consequently, the best application of a root graft may prove to be in the conversion of an occasional undesirable genotype.

In summary, grafts treated with IBA to promote union of the scion to the lateral root increased the survival of grafts made in late spring. At least two grafts per tree were necessary to maximize the percentage of trees on which cultivar conversion was $>75 \%$, although close to $90 \%$ might occur if both grafts are treated with IBA. Graft success is very dependent on the thickness of the root bark. Trees propagated onto lateral roots may become productive earlier than nursery-grown trees because of more rapid growth due to the extensive, well-developed root system. The long-term value of tree replacement by lateral root grafts is yet to be determined.

\section{Literature cited}

KenKnight, G.E. 1970. Pecan varieties "happen" in Jackson County, Mississippi. Pecan Quarterly 4(3):6-7. 
Soule, J. 1985. Glossary for horticultural crops. Wiley, New York.

Sparks, D. 1990. Inter-relationship of precocity, prolificacy, and percentage kernel in pecan. HortScience 25:297-299.
Sparks, D. and J.A. Payne. 1977. Freeze injury susceptibility of non-juvenile trunks in pecan. HortScience 12:497-498.

Westberry, G.O., W.O. Mizelle, and T.F. Crocker. 1989. Pecan production costs: Are your vari- eties profitable? Proc. Southeastern Pecan Growers Assn. p. 157-163.

Wood, B.W., J.A. Payne, and L.J. Grauke. 1990.

The rise of the U.S. pecan industry. Hort-

Science 25:594, 721-723. 